\title{
Fundamentals of Selective Laser Melting of alloyed steel powders
}

\author{
M. Rombouts ${ }^{1}$, J.P. Kruth ${ }^{2}(1)$, L. Froyen ${ }^{1}$ and P. Mercelis ${ }^{2}$ \\ ${ }^{1}$ Department of Metallurgy and Materials Engineering, Katholieke Universiteit Leuven, Leuven, Belgium \\ ${ }^{2}$ Department of Mechanical Engineering, Katholieke Universiteit Leuven, Leuven, Belgium
}

\begin{abstract}
The successful fabrication of dense iron-based parts by selective laser melting (SLM) is still limited to a narrow range of materials. This study aims at gaining an understanding of the effect of elements such as oxygen, carbon, silicon, titanium and copper on the quality of two-dimensional and three-dimensional ironbased objects. The results are related to the effect of the elements on physical phenomena such as laser absorption, heat transfer, wetting and spreading of the melt, oxidation, Rayleigh instability and Marangoni convection.
\end{abstract}

Keywords:

Selective Laser Melting (SLS), Powder, Alloy

\section{INTRODUCTION}

Selective laser melting (SLM) is a solid freeform fabrication process whereby a three-dimensional part is built layer wise by laser scanning a powder bed. The successful fabrication of dense iron-based parts by SLM is still limited to a narrow range of materials, among others some stainless steels and hot work steels. The complexity of the process and its non-equilibrium nature are responsible for the poor understanding of the process. The present study aims at providing a first step in unravelling the mystery about the difference in difficulty encountered during SLM of different types of steel powders. This is accomplished by investigating the effect of process parameters and alloying elements on the characteristics of single layers and three-dimensional parts fabricated by SLM. The effect of alloying elements such as copper, silicon, titanium and carbon is studied. Iron-based powders with a higher carbon content yield after SLM a higher density according to [1] while the opposite is observed in [2] and [3].

\section{EXPERIMENTAL CONDITIONS}

A 'Concept Laser M3 Linear' SLM machine equipped with a Nd:YAG laser having a beam diameter of $0.2 \mathrm{~mm}$ and a maximal output power $(P)$ of $95 \mathrm{~W}$ is used. A scan spacing $(S)$ of $0.14 \mathrm{~mm}$ and scan speeds $(V)$ from 10 $\mathrm{mm} / \mathrm{s}$ to $300 \mathrm{~mm} / \mathrm{s}$ are applied. The contour of the layers is scanned before the core, which is always scanned entirely along the same scanning direction. The single layers are $10 \mathrm{~mm}$ by $25 \mathrm{~mm}$. The 3D parts, which are built with a layer thickness $(I)$ of $70 \mu \mathrm{m}$, are $15 \mathrm{~mm}$ by $15 \mathrm{~mm}$ and $5 \mathrm{~mm}$ high. The tests are executed in a $\mathrm{N}_{2}$ atmosphere with a residual oxygen content $\left(\% \mathrm{O}_{a t m}\right)$ of $0.5 \%$ unless stated otherwise.

Table 1 describes the different powder alloys that were used in this investigation.

The density of SLM parts is determined by using Archimedes' method. The roughness of the top surface is measured perpendicular to the scanning direction. The result of 5 measurements taken along an evaluation length of $10 \mathrm{~mm}$ and without the use of a cut-off filter is presented. The carbon and oxygen contents of the materials are obtained using respectively a Coulomat 702
SO/CS and a NOA 5003 (Emerson - Fisher Rosemount) apparatus.

\begin{tabular}{|l|l|}
\hline & \multicolumn{1}{|c|}{ description } \\
\hline Powder 1 & $\begin{array}{l}\text { water atomised pure Fe powder (Höganäs: } \\
\text { type ASC300, 0.1 wt\% oxygen), } d_{50}=58 \\
\mu \mathrm{m}\end{array}$ \\
\hline Powder 2 & $\begin{array}{l}\text { powder 1 + gas atomised Fe }-3 \mathrm{wt} \% \mathrm{C} \\
\text { powder }\left(d_{50}=39 \mu \mathrm{m}\right): 0.8 \mathrm{wt} \% \mathrm{C} \text { and 0.1 } \\
\text { wt\% O in total }\end{array}$ \\
\hline Powder 3 & powder 2 + 1 wt\% Si $\left(d_{50}<8 \mu \mathrm{m}\right)$ powder \\
\hline Powder 4 & $\begin{array}{l}\text { powder 2 }+2.5 \mathrm{wt} \% \mathrm{Cu}\left(d_{50}=30 \mu \mathrm{m}\right) \\
\text { powder }\end{array}$ \\
\hline Powder 5 & $\begin{array}{l}\text { powder 2 + gas atomised Fe }-30 \mathrm{wt} \% \mathrm{Cu} \\
\text { powder }\left(d_{50}=36 \mu \mathrm{m}\right): \text { in total } 2.5 \mathrm{wt} \% \mathrm{Cu}\end{array}$ \\
\hline Powder 6 & powder 4 $+1 \mathrm{wt} \% \mathrm{Ti}\left(d_{50}<25 \mu \mathrm{m}\right)$ powder \\
\hline Powder 7 & powder 4 + 1 wt\% Si $\left(d_{50}<8 \mu \mathrm{m}\right)$ powder \\
\hline
\end{tabular}

Table 1: description of the tested powders

\section{SINGLE LINES AND LAYERS}

A first phenomenon that is observed during scanning of single lines and layers involves balling of the melt. This is probably caused by Rayleigh instability and/or Marangoni convection. The former implies the break up of a liquid cylinder with high aspect ratio in order to lower the surface energy [4]. This type of instability was first studied by Plateau. He stated that in zero gravity a free liquid cylinder is unstable if the ratio of its length $L$ to diameter $W$ exceeds $\pi$. The dynamics of this process was later studied by Rayleigh for liquids with negligible viscosity [5]. This condition is satisfied for metals at temperatures above the liquidus temperature. His calculations point out that the time to break up is minimal if $\pi W / \lambda=0.697$ with $\lambda$ the wavelength of a sinusoidal perturbation of the diameter. The break up time is then equal to:

$$
t_{\text {break }}=\left\{0.3433 \cdot \sqrt{\gamma_{L V} /\left[\rho(W / 2)^{3}\right]}\right\}^{-1},
$$

with $\gamma_{L V}$ the surface tension and $\rho$ the density of the liquid [4]. The break up time of a Fe melt pool with $W=0.4 \mathrm{~mm}$ is according to Equation (1) about $0.5 \mathrm{~ms}$ at the melting 
point of Fe. This is well below the typical solidification time during SLM. Equation (1) also reveals that alloying elements do not significantly alter the dynamics of Rayleigh instability by only changing $\gamma_{L V}$ of Fe since this only affects $t_{\text {break }}$ in the order of tenths of a millisecond [6]. However, alloying elements significantly alter the kinetics of the break up process if they lead to the formation of a highly viscous semi-solid zone between the solidus and liquidus temperature [7]. For liquids with a relatively high viscosity $\eta$, the minimal break up time increases and the ratio $\pi W / \lambda$ at which the break up time is minimal decreases with decreasing values of the dimensionless number $J[4]$ :

$$
J=\gamma_{L V} \rho W / \eta^{2}
$$

A higher viscosity $\eta$ thus increases the break time and results in larger droplets with a larger spacing in between. Marangoni convection is the thermocapillary flow of a fluid from regions with a low surface tension to regions with a high surface tension. The sign of the surface tension gradient $\mathrm{d} \gamma_{L V} / \mathrm{d} T$ of the liquid determines the direction of the fluid flow, as shown schematically in Figure 1. If the flow is radially outward as in Figure 1(a) a shallow and broad melt pool results. If the flow is radially inward (Figure 1(b)) a deep but narrow pool is formed. The surface tension gradient $\mathrm{d} \gamma_{L V} / \mathrm{d} T$ of pure metals and many alloys is negative. However, positive $d \gamma_{L V} / \mathrm{d} T$ are reported for alloys containing a sufficiently high content of surface active elements. Examples are iron-based liquids with sulphur or oxygen concentrations exceeding a critical level [6]. The magnitude of the flow can be estimated from the dimensionless Marangoni number $M_{a}$ :

$$
M_{a}=\frac{\mathrm{d} \gamma_{L V}}{\mathrm{~d} T} \frac{\mathrm{d} T}{\mathrm{~d} r} \frac{L}{2 \eta \delta},
$$

with $\mathrm{d} T / \mathrm{d} r$ the temperature gradient, $L$ the characteristic length of the melt pool and $\delta$ the thermal diffusivity [8]. Niu et al. [9] observed that high speed steel powders with 0.10 wt $\%$ O exhibit a higher tendency to balling during SLM than those with an oxygen content of only $0.02 \mathrm{wt} \%$ [10]. They attributed this tendency to the larger radially inward Marangoni flow caused by the larger positive value of the surface tension gradient $\mathrm{d} \gamma_{L V} / \mathrm{d} T$ of liquid $\mathrm{Fe}$ at higher dissolved oxygen contents [6].

\subsection{Fe powder}

The experiments indicate that at low scan speeds $(V)$ no balling occurs and smooth layers are formed (Figure 2(a)). At intermediate $\boldsymbol{V}$ balling leads to irregular layers consisting of cylindrical zones oriented perpendicular to the scanning direction (Figure 2(b)). They result from the overlap between balls formed in subsequent scan tracks. At high $\mathbf{V}$, the layers are made up of individual droplets since the lower heat input yields smaller balls that do not overlap (Figure 2(c)).

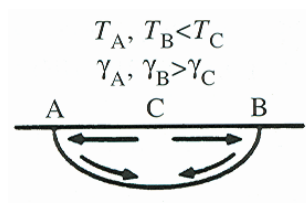

(a) $\mathrm{d} \gamma_{L V} / \mathrm{d} T<0$

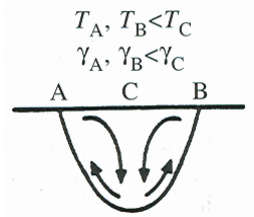

(b) $d \gamma_{L V} / d T>0$
Figure 1: Schematic presentation of Marangoni convection in a melt due to the presence of a surface tension gradient $\mathrm{d} \gamma_{L V} / \mathrm{d} T$ [10].

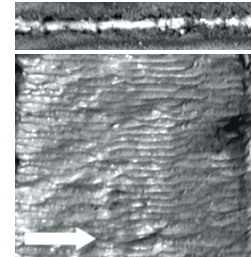

(a) $V=10 \mathrm{~mm} / \mathrm{s}$

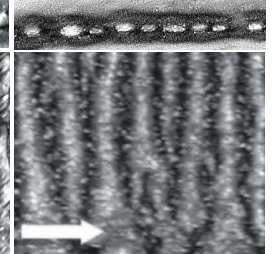

(b) $V=100 \mathrm{~mm} / \mathrm{s}$

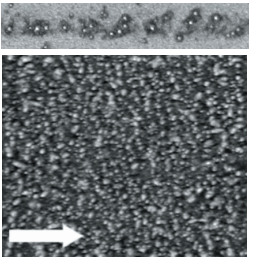

(c) $V=300 \mathrm{~mm} / \mathrm{s}$
Figure 2: Single lines (top) and layers (bottom) produced at $S=0.14 \mathrm{~mm}, P=95 \mathrm{~W}$ and $\% \mathrm{O}_{a t m}=3 \%$. The arrow depicts the scanning direction. The width of the layers is $10 \mathrm{~mm}$.

A higher oxygen content in the atmosphere $\left(\% \mathrm{O}_{\mathrm{atm}}\right)$ results in larger and more spherical droplets when scanning lines (Figure 3 ). Consequently when scanning layers broader elongated zones are formed (Figures 4(a),(b)). Oxygen is initially present in the Fe powder as impurity element $(0.10 \mathrm{wt} \%)$ but is also picked up during SLM due to the presence of residual oxygen in the atmosphere. The dissolved oxygen content in the Fe melt during SLM might be higher than the initial oxygen content since the equilibrium oxygen concentration in liquid $\mathrm{Fe}$ is $\sim 0.4$ wt $\%$ at $1700^{\circ} \mathrm{C}$ [11]. Upon cooling and at oxygen contents exceeding the maximal dissolved oxygen content $\mathrm{Fe}$ oxides are formed by exothermic oxidation. E.g., the formation of $\mathrm{FeO}$ due to oxidation of $\mathrm{Fe}$ with $\mathrm{O}_{2}$ is accompanied by an energy release of $2.4 \mathrm{~kJ} / \mathrm{g} \mathrm{Fe}$. Since oxidation is more likely to occur at higher temperatures most of the heat is released near the melt pool. This enlarges the melt pool if enough $\mathrm{Fe}$ is oxidised so that the released energy is not negligible compared to the latent heat of fusion, which is for Fe $0.25 \mathrm{~kJ} / \mathrm{g}$. The increase in melt volume is furthermore promoted by the slight decrease in melting point and increase in solidification range [11] and counteracted by the lower laser absorptance if oxides are present in the irradiated surface area [12]. The surface tension gradient $d \gamma_{L V} / d T$ of liquid $\mathrm{Fe}$ does not change with increasing oxygen content for wt $\%$ O higher than $0.1 \mathrm{wt} \%$ [6]. The oxygen content in the atmosphere does consequently not affect Marangoni convection in the melt pool in this way.

\section{$3.2 \mathrm{Fe}-\mathbf{0 . 8 \%} \mathrm{C}-(\mathrm{Cu}, \mathrm{Si}, \mathrm{Ti})$ powder}

The addition of $\mathrm{Fe}-3 \mathrm{wt} \% \mathrm{C}$ powder yields in the entire process window smoother layers (Figure 4(c)). No cylindrical densified zones oriented perpendicular to the scanning direction are formed. The effect of carbon on the thermal properties of $\mathrm{Fe}$ involves mainly a lower melting point and an increased solidification range [11]. The addition of $\mathrm{C}$ under the form of prealloyed $\mathrm{Fe}-3 \% \mathrm{C}$, which starts to melt at $1147^{\circ} \mathrm{C}$, increases furthermore the semi-solid zone at the border of the melt pool. This viscous zone complicates the break up of the melt pool by Rayleigh instability (see above). $\mathrm{C}$ has, above the melting temperature of $\mathrm{Fe}$, a high tendency to oxidise [13]. This tends to lower the dissolved oxygen content. Although the surface tension gradient $\mathrm{d} \gamma_{L V} / \mathrm{d} T$ of $\mathrm{Fe}$ is not directly affected by carbon [6], the indirect effect related to its deoxidising character tends to decrease $d \gamma_{L V} / d T$ yielding a smaller detrimental Marangoni flow.

Adding $1 \mathrm{wt} \%$ silicon deteriorates the quality of a $\mathrm{Fe}-$ $0.8 \% \mathrm{C}$ layer to a high extent (Figure $4(\mathrm{~d})$ ). In [14] it is reported that Si has a detrimental effect on the melt pool

\begin{tabular}{|c|c|}
\hline 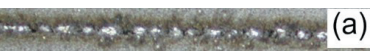 & e crase e teceich (b) \\
\hline $0.1 \% \mathrm{O}_{a t m} \quad 5 \mathrm{~mm}$ & $3 \% \mathrm{O}_{a t m}$ \\
\hline
\end{tabular}
stability of $\mathrm{Fe}$ and yields a larger melt volume.

Figure 3: Single Fe lines produced at $V=50 \mathrm{~mm} / \mathrm{s}$ and $P$ $=95 \mathrm{~W}$. 


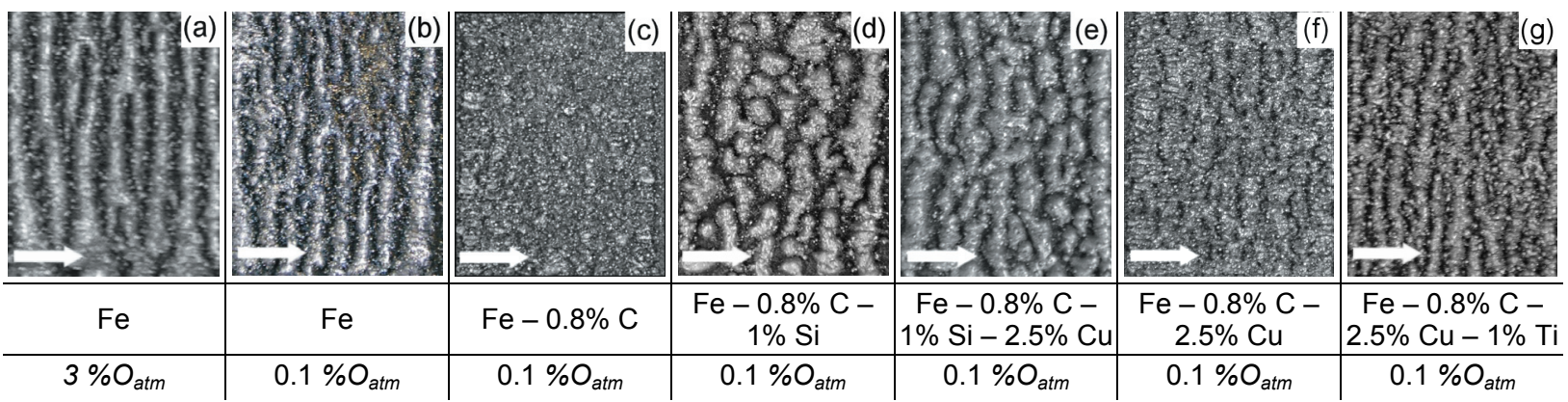

Figure 4: Single layers produced with $P=95 \mathrm{~W}, V=100 \mathrm{~mm} / \mathrm{s}$ and $S=0.14 \mathrm{~mm}$. The arrow depicts the scanning direction. The width of the layers is $10 \mathrm{~mm}$.

A higher degree of melting is promoted by oxidation of $\mathrm{Si}$ in a similar way as by $\mathrm{Fe}$ oxide formation (see above). The standard free energy of the reaction of $\mathrm{Si}$ with $\mathrm{O}_{2}$, which gives an indication about the heat release accompanied with oxidation of Si present in a $\mathrm{Fe}-\mathrm{C}-\mathrm{Si}$ material, is at $1727^{\circ} \mathrm{C} 18.5 \mathrm{~kJ} / \mathrm{g} \mathrm{Si}$, which is significantly higher than in case of $\mathrm{Fe}$ oxidation (see above) [13]. SiC formation results in an additional heat release. Microstructural and chemical analyses confirm the formation of a large amount of Si containing inclusions. The increase in melt volume is furthermore promoted by the high absorptance of $\mathrm{SiC}$ and counteracted by the low absorptance of $\mathrm{SiO}_{2}$ for $\mathrm{Nd}$ :YAG radiation [12]. Although $\mathrm{Si}$ has a higher absorptance $(\sim 67 \%)$ than steel $(\sim 59 \%)$ for Nd:YAG radiation no significant impact on the absorptance of the $\mathrm{Fe}-0.8 \% \mathrm{C}$ powder is expected because of the low $\mathrm{Si}$ concentration. Si has only a significant effect on the melting point and solidification range of $\mathrm{Fe}-0.8 \% \mathrm{C}$ due to its tendency to form $\mathrm{SiC}$. This reduces the amount of $\mathrm{C}$ in solid solution with $\mathrm{Fe}$ and decreases in this way the solidification range and increases the melting point. The former reduces the viscosity at the border of the melt pool and favours the kinetics of Rayleigh instability. On the other hand, if solid oxides and carbides are present in the melt an increase in viscosity is expected. Si tends to reduce the dissolved oxygen content and in this way to reduce the surface tension gradient of liquid $\mathrm{Fe}$ and the detrimental Marangoni flow due to its deoxidising character. However, since a less stable melt pool is observed, this factor will be of minor importance.

The morphology of a $\mathrm{Fe}-0.8 \% \mathrm{C}$ layer is not significantly changed by the presence of copper (Figure 4(f)). The addition of $\mathrm{Cu}$ to the $\mathrm{Fe}-0.8 \% \mathrm{C}-1 \% \mathrm{Si}$ powder yields a layer with less isolated molten zones (Figure 4(e)).

Titanium, which has an even higher tendency to react with $\mathrm{O}$ and $\mathrm{C}$ than $\mathrm{Si}$ [13], is added to the $\mathrm{Fe}-\mathrm{C}-\mathrm{Cu}$ powder in order to assess whether the detrimental effect of $\mathrm{Si}$ is linked to its high tendency to form oxides and carbides. Ti has compared to $\mathrm{Si}$ a higher melting point $\left(1670^{\circ} \mathrm{C}\right)$ and a lower laser absorptance $(40 \%)$. The effect of $1 \mathrm{wt} \%$ dissolved $\mathrm{Ti}$ on the thermal properties of $\mathrm{Fe}$ is negligible. As with $\mathrm{Si}$ a more irregular layer, which is formed due to the higher tendency to balling, is formed (Figure 4(g)). These observations suggest that the exothermic formation of oxides and carbides plays an important role with regards to instability of the melt pool.

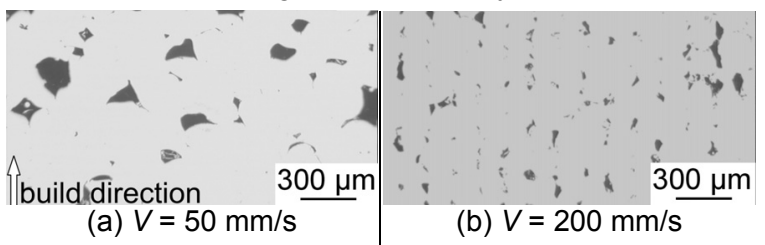

Figure 5: Cross section of Fe parts taken perpendicular to the scanning direction. The parts are produced with $P=$ $95 \mathrm{~W}, I=70 \mu \mathrm{m}, S=0.14 \mathrm{~mm}$ and $\% O_{a t m}=0.5 \%$.

\subsection{Validation by in-process observation}

To validate the experimental results, an in-process monitoring system was used. The monitoring system was installed on an own developed SLM machine that was recently equipped with a $300 \mathrm{~W}$ CW fiber laser. As a result, different power and speed values had to be used than in the tests of paragraphs 3.1 and 3.2. However, the results obtained from the in process observation can still be qualitatively compared with the previous experiments.

The monitoring system consists of a high speed CMOS camera that records the melt pool images. The optical path of the laser radiation and the optical path of the camera are combined before the laser scanner by means of wavelength dependent mirror (Figure 6). Therefore, the camera observes a small zone around the laser spot, regardless of the scanner movement. It is thus possible to monitor the melt pool during the SLM process at any moment.

The laser wavelength of $1070 \mathrm{~nm}$ is reflected by the 45 degree mirror, and is directed to the scan head. On the other hand, wavelengths in the visual and near-IR range $(400-950 \mathrm{~nm})$ are transmitted by the mirror. Thus, the visual and near-IR fraction of the melt pool radiation is transmitted trough the mirror and captured by the CMOS camera. Optical filters are placed before the camera to eliminate any possible reflected laser light and to limit the wavelength-band to reduce chromatic aberrations and to reduce the incident intensity. All image sequences were recorded at a frame rate of $250 \mathrm{fps}$, and an exposure time of $2.5 \mathrm{~ms}$.

Since the emissivity of the melt pool is not known, the recorded pixel grey levels cannot be mapped to an exact temperature. However, the grey level corresponding to the melt-isotherm can be distinguished by observation of the isothermal lines [15].

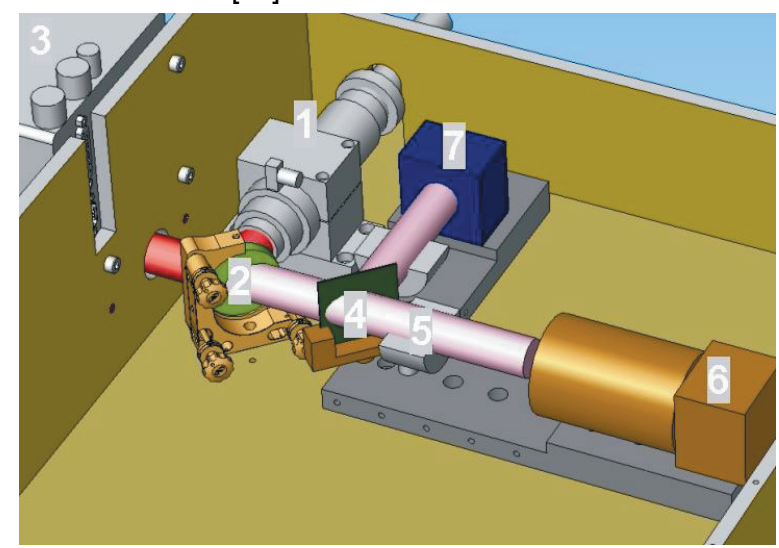

Figure 6: Coaxial monitoring system for SLM monitoring (1: fiber laser output collimator, 2: $45^{\circ}$ mirror, 3: laser scanner, 4: beam splitter, 5: optical filters, 6: CMOS camera, 7: photodiode module). 


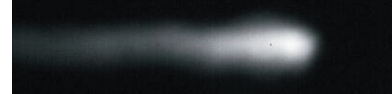

(a) grey scale image

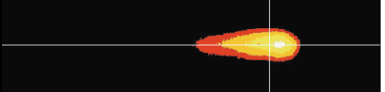

(b) processed image
Figure 7: Typical melt pool images.

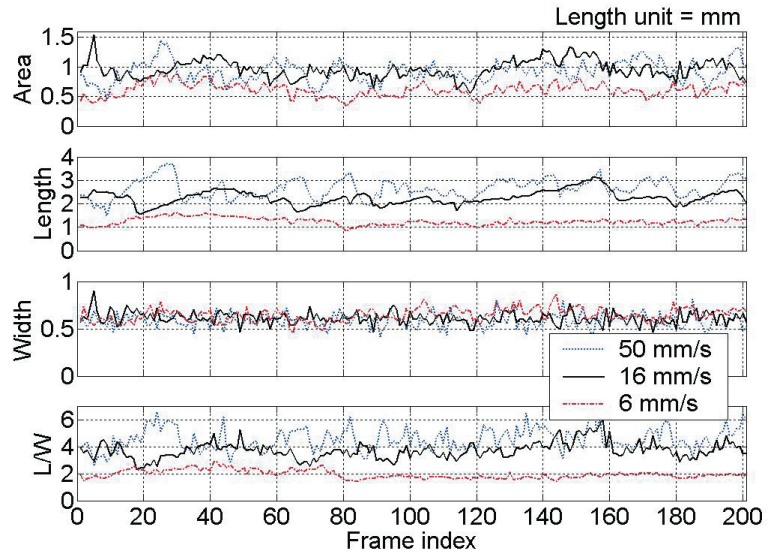

Figure 8: Influence of scanning speed on the melt pool geometry of Fe.

Having determined the melt temperature grey level, the melt pool's geometric characteristics can be determined. Figure 7(a) shows a typical example of a melt pool image. In Figure 7(b) the processed image is shown; a threshold is set at the melt temperature grey level and the length and width of the melt pool is indicated by the white lines.

As discussed in paragraph 3.1 , the scan speed and the oxygen content of the atmosphere influence the occurrence of balling during SLM of Fe powder. This was validated by scanning single tracks in loose Fe powder (powder 1) at different speeds and at different oxygen levels. Figure 8 presents the influence of the source speed on the melt pool geometry. All melt pool area values are in $\mathrm{mm}^{2}$, length and width values in $\mathrm{mm}$. The length to width ratio (L/W) is dimensionless. It can be seen that - in the speed range considered - an increase in scan speed leads to an increase in melt pool size $e^{1}$. This increase in size is mainly caused by an increase in melt pool length; the melt pool width remains almost constant. Thus, the length to width ratio increases, resulting in Rayleigh instability and balling. The instability is reflected in a larger variance of the melt pool dimensions for the 50 $\mathrm{mm} / \mathrm{s}$ scan track than for the $6 \mathrm{~mm} / \mathrm{s}$ track. Figure 9 illustrates the melt pool instability. The bottom image shows the melt pool breaking up into smaller droplets.

The effect of the oxygen content in the atmosphere is illustrated in Figure 10. It can be seen that under an air atmosphere, the melt pool area enlarges compared with an inert $\mathrm{N}_{2}$ atmosphere. The length increase is in general greater than the increase in melt pool width, thus also the tendency to balling due to Rayleigh instability increases as illustrated in Figure 11.

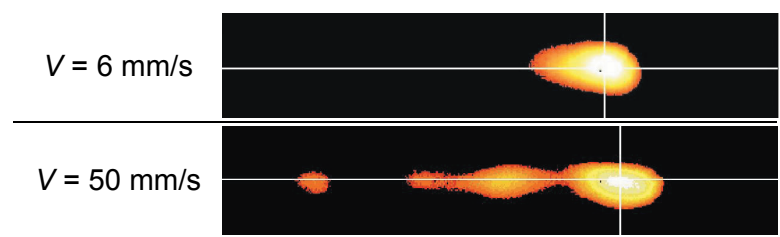

Figure 9: Melt pool images for Fe under inert atmosphere.

\footnotetext{
${ }^{1}$ At higher speed levels, the melt pool area reduces with increasing scanning speed
}

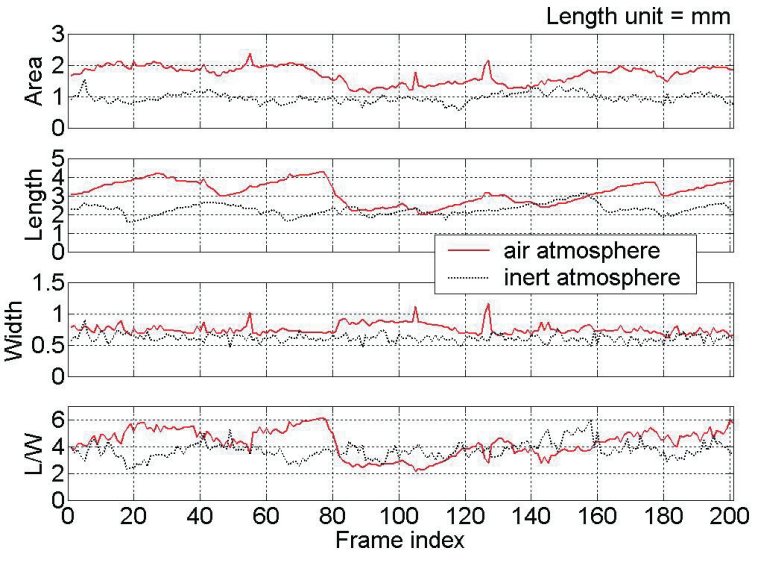

Figure 10: Effect of the oxygen content in the atmosphere on the melt pool geometry for Fe at $V=16 \mathrm{~mm} / \mathrm{s}$.

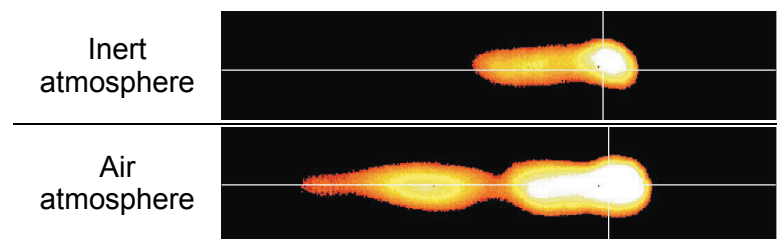

Figure 11: Melt pool images for Fe at $V=16 \mathrm{~mm} / \mathrm{s}$.

The detrimental effect of the addition of silicon that was discussed in paragraph 3.2 , is confirmed by the melt pool observation experiments. Figure 12 represents the melt pool geometry for two identical experiments with powder 1 (pure Fe) and powder 1 mixed with 1 wt \% Si powder $\left(d_{50}\right.$ $<8 \mu \mathrm{m}$ ). It is clear that the addition of $1 \mathrm{wt} \%$ Si leads to a huge increase in melt pool area due to an exothermal oxidation reaction. Again, the length increase is larger than the width increase, leading to a high degree of Rayleigh instability. This can be clearly seen in Figure 13, which should be compared with the top image in Figure 11. It is important to notice that both experiments in Figure 12 were performed under an inert $\mathrm{N}_{2}$ atmosphere. However, processing $\mathrm{Fe}-1$ wt $\%$ Si under air atmosphere leads to nearly the same melt pool geometry. It can thus be concluded that the rest oxygen percentage in the inert $\mathrm{N}_{2}$ atmosphere is still high enough to oxidize all the Si.

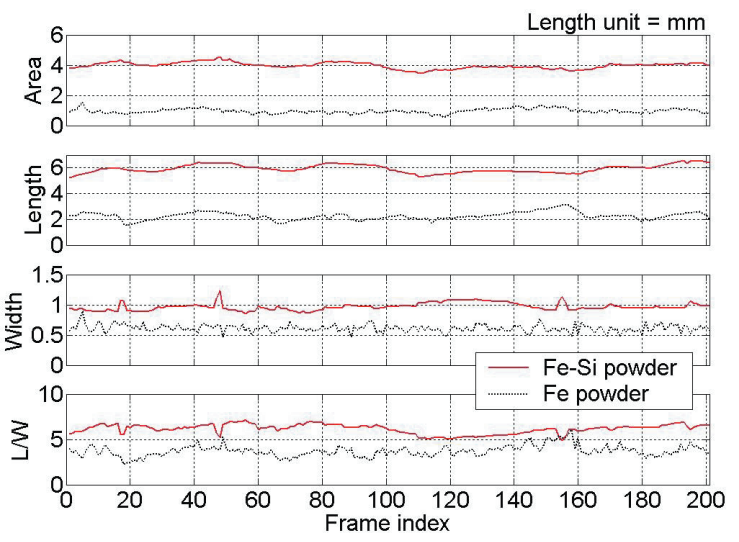

Figure 12: Effect of $1 \mathrm{wt} \% \mathrm{Si}$ addition on the melt pool geometry at $V=16 \mathrm{~mm} / \mathrm{s}$ under inert atmosphere.

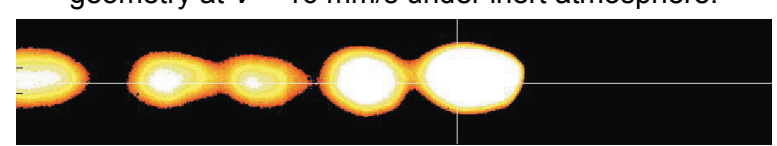

Figure 13: Melt pool image at $V=16 \mathrm{~mm} / \mathrm{s}$ under inert atmosphere for $\mathrm{Fe}-1 \mathrm{wt} \% \mathrm{Si}$. 


\section{THREE DIMENSIONAL PARTS}

\subsection{Fe powder}

The microstructure consists of fine ferritic grains, oxide inclusions and pores. The pore structure depends on the applied scan speed (V) (Figure 5). At intermediate $V$ dense zones slanted with regards to the building direction are formed (Figure 5(a)). The top surface of the parts reveals the presence of continuous tracks with a width of several times the scan spacing $S$. The pores are located between neighbouring solidified tracks. The pores are probably the result of the capillary attraction of powder particles to the large melt pool yielding zones deficient in powder next to the melt pools. This type of pore and surface morphology is more pronounced when processing in an atmosphere with higher oxygen content $\left(\% \mathrm{O}_{a t m}\right)$. The higher amount of oxidation enlarges the melt pool, which attracts consequently more powder particles. The part shown in Figure $5(\mathrm{a})$ has an oxygen content of 0.28 wt $\%$ and a relative density of $93 \%$ (Figure 14). The part produced with the same parameters except from $\% \mathrm{O}_{a t m}$, which is $3 \%$ instead of $0.5 \%$, has an oxygen content of $0.41 \mathrm{wt} \%$ and a relative density of only $84 \%$. The broad ripples at the top surface are also formed at low $\boldsymbol{V}(\sim 10$ $\mathrm{mm} / \mathrm{s}$ ) but they give rise to less pores. At high $\boldsymbol{V}$, the melt pools have a width equal to the scan spacing. The pores are oriented along the building direction and located at the position where the overlap between neighbouring melt pools vanishes (Figure $5(\mathrm{~b})$ ). The dependence of the density on $V$ is larger in the range where the overlap vanishes $(V>100 \mathrm{~mm} / \mathrm{s})$ (Figure 14).

\section{$4.2 \mathrm{Fe}-0.8 \% \mathrm{C}-(\mathrm{Cu}, \mathrm{Si}, \mathrm{Ti})$ powder}

Parts are produced at a laser power of $95 \mathrm{~W}$ and scan speeds between $50 \mathrm{~mm} / \mathrm{s}$ and $300 \mathrm{~mm} / \mathrm{s}$. The microstructures are mainly martensitic.

The $\mathbf{F e}-\mathbf{0 . 8 \%} \mathrm{C}$ parts have about the same relative density (Figure 14) but a different pore (Figure 15) and surface morphology than the Fe parts. The pores are at all scan speeds randomly distributed. The large amount of spherical pores (Figure 15) mainly originates from the entrapment of $\mathrm{CO}$ or $\mathrm{CO}_{2}$ gas formed by oxidation of $\mathrm{C}$. This is indicated by chemical analysis, which reveals that a $C$ loss occurs during SLM and that the $O$ content of the $\mathrm{Fe}-0.8 \% \mathrm{C}$ parts is in general lower than of the Fe parts while the powders have the same oxygen content. The $\mathrm{O}$ content of the Fe part shown in Figure $5(a)$ is 0.28 wt $\%$ while it is only $0.04 \mathrm{wt} \%$ for the $\mathrm{Fe}-0.8 \% \mathrm{C}$ part shown in Figure 15(a).

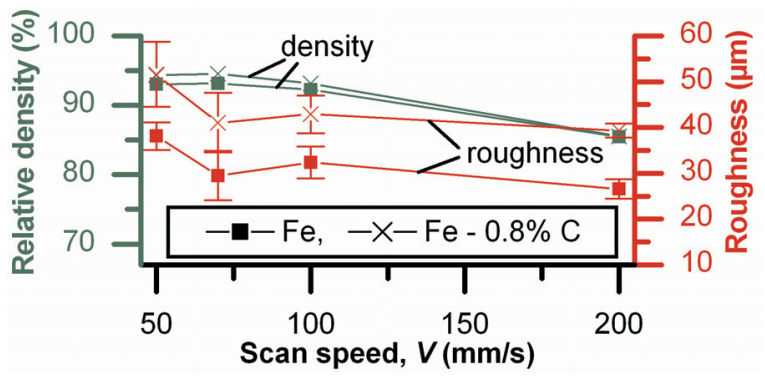

Figure 14: Relative density and roughness of the top surface of $\mathrm{Fe}$ and $\mathrm{Fe}-0.8 \% \mathrm{C}$ parts fabricated with $P=$ $95 \mathrm{~W}, I=70 \mu \mathrm{m}, S=0.14 \mathrm{~mm}$ and $\% O_{a t m}=0.5 \%$.

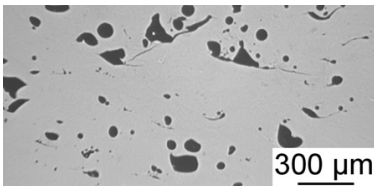

(a) $V=50 \mathrm{~mm} / \mathrm{s}$

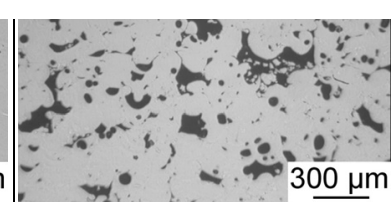

(b) $V=200 \mathrm{~mm} / \mathrm{s}$
Figure 15: Cross section of $\mathrm{Fe}-0.8 \% \mathrm{C}$ parts taken perpendicular to the scanning direction. The parts are produced with $P=95 \mathrm{~W}, I=70 \mu \mathrm{m}, S=0.14 \mathrm{~mm}$ and

$$
\% \mathrm{O}_{a t m}=0.5 \% \text {. }
$$

For the latter the $\mathrm{C}$ loss is $\sim 0.07 \%$. The roughness of the top surface is higher than that for the Fe parts (Figure 14). At low $V$ broader tracks are formed than in the Fe parts. At high $V$ the melt pools are broken up. The reduction in irregular porosity compared to Fe (Figures 5(a), 15(a)) is promoted by the lower melting point, higher solidification range and the lower amount of oxides, which enhances the wetting behaviour.

Silicon is added to the $\mathrm{Fe}-0.8 \% \mathrm{C}$ powder with the aim to diminish the spherical porosity caused by oxidation of C. The spherical porosity is indeed diminished to a high extent (Figures 15(a), 16(a)). A carbon loss of $0.11 \%$ and an oxygen content of $0.105 \%$ is detected for the part shown in Figure 16(a) while without Si the carbon loss and the oxygen content are respectively $0.07 \%$ and $0.04 \%$. The larger carbon loss indicates that $\mathrm{Si}$ did not suppress oxidation of $\mathrm{C}$, on the contrary even. This is possible if the temperature of the $\mathrm{Fe}-\mathrm{C}-\mathrm{Si}$ melt is higher than of the $\mathrm{Fe}-\mathrm{C}$ melt since oxidation of $\mathrm{C}$ is favoured at higher temperatures [13]. A higher temperature is promoted by the larger amount of exothermic oxidation, as revealed by the larger carbon loss and higher oxygen content in presence of $\mathrm{Si}$. The lower spherical porosity points out that although more $\mathrm{CO}$ and $\mathrm{CO}_{2}$ is formed, less gas bubbles are entrapped in the material. The escape of gas is facilitated by the presence of large irregular pores (Figure 16(a)). The larger amount of $\mathrm{C}, \mathrm{Si}$ and/or $\mathrm{Fe}$ oxidation is accompanied by a larger heat release, which increases the life time of the melt and makes in this way the escape of gas also more effective than in a $\mathrm{Fe}-\mathrm{C}$ material. Furthermore, the melt has at higher temperatures a lower viscosity, which facilitates the escape of gas. The roughness of the surface tends to be higher in presence of Si (Figure 18), which might also result from the larger melt volume. The attraction of powder particles to the large melt pools and the worse wetting due to the presence of oxides and/or carbides favour the formation of irregular pores in the $\mathrm{Fe}-\mathrm{C}-\mathrm{Si}$ parts.

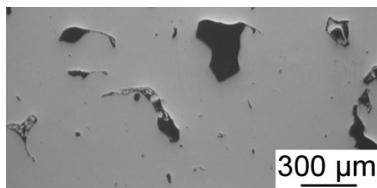

(a) $1 \% \mathrm{Si}$

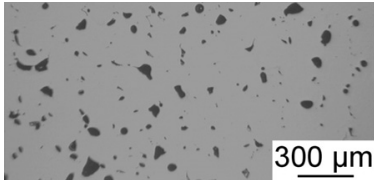

(c) $8.3 \%(\mathrm{Fe}-30 \% \mathrm{Cu}) \rightarrow$ $2.5 \%$ Cu final

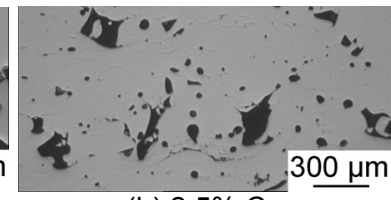

(b) $2.5 \% \mathrm{Cu}$

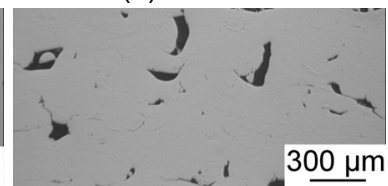

(d) $2.5 \% \mathrm{Cu}, 1 \% \mathrm{Ti}$
Figure 16: Cross sections taken perpendicular to the scanning direction of parts produced with $P=95 \mathrm{~W}, I=70$ $\mu \mathrm{m}, S=0.14 \mathrm{~mm}, V=50 \mathrm{~mm} / \mathrm{s}$ and $\% \mathrm{O}_{\mathrm{atm}}=0.5 \%$. The amount of powders mixed with the $\mathrm{Fe}-0.8 \% \mathrm{C}$ powder mixture are given. 


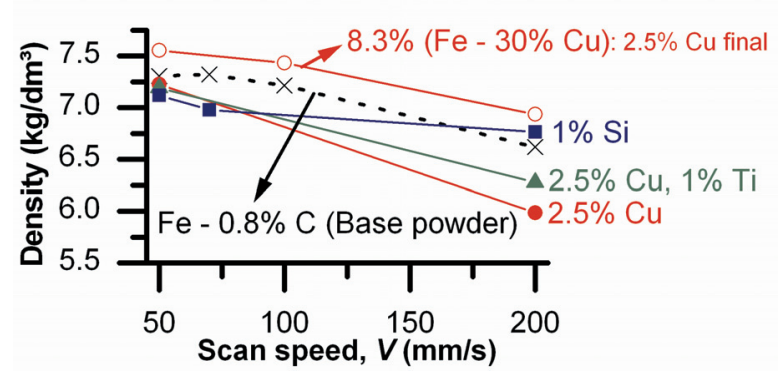

Figure 17: Density of parts produced with $P=95 \mathrm{~W}, I=70$ $\mu \mathrm{m}, S=0.14 \mathrm{~mm}$ and $\% \mathrm{O}_{a t m}=0.5 \%$. The amount of powders mixed with the $\mathrm{Fe}-0.8 \% \mathrm{C}$ powder mixture are given.

The addition of $2.5 \mathrm{wt} \%$ pure copper powder causes a substantial decrease in density at high $V$ (Figure 17) and a decrease in surface roughness (Figure 18). More irregular pores are formed (Figure 16(b)), probably due to the high reflectivity of $\mathrm{Cu}$ for $\mathrm{Nd}$ :YAG laser radiation since when prealloyed $\mathrm{Fe}-30 \% \mathrm{Cu}$ is added a significantly higher density is attained at all $V$ (Figures 5(a), 16(c), 17).

Titanium, which like $\mathrm{Si}$ has a high tendency to form oxides and carbides, is added to the $\mathrm{Fe}-0.8 \% \mathrm{C}-2.5 \%$ $\mathrm{Cu}$ powder. The same general conclusions as in case of $\mathrm{Si}$ can be drawn. The roughness of the top surface tends to increase (Figure 18), the spherical porosity is reduced to a high extent but large irregular pores remain present (Figures 16(b),(d)). This supports the hypothesis that exothermic reactions play a major role in SLM of steel powders containing deoxidisers as $\mathrm{Si}$ and $\mathrm{Ti}$.

\section{CONCLUSIONS}

Oxygen in the atmosphere of the SLM chamber increases the melt volume formed during SLM due to exothermic oxidation of $\mathrm{Fe}$. This deteriorates the surface quality of single layers and 3D parts.

Balling of $\mathrm{Fe}$ is only observed during the fabrication of single layers. Its absence in 3D parts is probably caused by the smaller melt volume during production of $3 D$ parts due to the higher heat conduction through the baseplate used in 3D SLM and through the previously densified layers. At intermediate scan speeds $V$ dense zones slanted with regards to the building direction are formed due to the formation of broad melt pools that attract powder particles lying next to it. At high $V$ insufficient overlap between neighbouring scan tracks yields porous zones oriented along the building direction.

Carbon ameliorates the surface quality of single layers in contrast to $3 \mathrm{D}$ parts. Randomly distributed pores are present in the $\mathrm{Fe}-0.8 \% \mathrm{C}$ parts. Spherical pores result from entrapped $\mathrm{CO}$ or $\mathrm{CO}_{2}$ gas formed by oxidation of $\mathrm{C}$. The lower melting point, higher solidification range and lower amount of iron oxides, which improves the wetting behaviour, tend to reduce the irregular porosity.

Silicon and titanium have a negative effect on the surface quality of single layers and three-dimensional Fe-based parts. Both elements increase the irregular porosity. Their detrimental effect is attributed to their high tendency to form oxides and carbides.

Copper does not affect the melt pool behaviour of $\mathrm{Fe}-$ $0.8 \%$ C during SLM of a single layer. It has a negative effect on the densification if added as pure powder due to the high reflectivity of $\mathrm{Cu}$ for $\mathrm{Nd}$ :YAG laser radiation but a positive effect if added in prealloyed form.

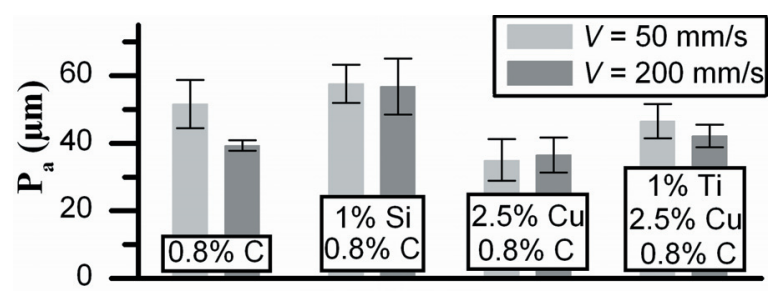

Figure 18: Roughness of the top surface of Fe-based parts produced at $P=95 \mathrm{~W}, I=70 \mu \mathrm{m}, S=0.14 \mathrm{~mm}$ and $\% \mathrm{O}_{\mathrm{atm}}=0.5 \%$.

\section{ACKNOWLEDGEMENTS}

Research supported by funding from KULeuven-GOA.

\section{REFERENCES}

[1] Simchi, A., Pohl, H., 2004, Direct laser sintering of iron-graphite powder mixture, Materials Science and Engineering, A 383:191-200.

[2] Rombouts, M., Froyen, L., Van Vaerenbergh, J., Mercelis, P., 2004, Production and properties of dense iron based parts produced by laser melting with plasma formation, Proc. of World Powder Metallurgy Conference PM2004, 5:115-121.

[3] Xie, J.W., Fox, P., Chen, X.C., O'Neill, W., Wright, C.S., Yousseffi, M., Hauser, C., Dalgrano, K., Childs, T.H.C., 2003, Direct laser remelting of tool steels, Proc. of European Powder Metallurgy Conference PM2003, 3:473-478.

[4] Chandrasekhar, S., 1970, Hydrodynamic and hydromagnetic stability, Clarendon Press, Oxford.

[5] Lord Rayleigh, 1892, On the instability of a cylinder of viscous liquid under capillary force, Philosophical Magazine, 34/207:145-154

[6] Keene, B.J., 1988, Review of data for the surface tension of iron and its binary alloys, International Materials Review, 33/1:1-36.

[7] Joly, P.A., Mehrabian, R., 1976, The rheology of a partially solid alloy, J. Mat. Science, 11:1393-1418.

[8] Lu, S., Fuji, H., Nogi, K., 2004, Marangoni convection and weld shape variations in $\mathrm{Ar}-\mathrm{O}_{2}$ and Ar- $\mathrm{CO}_{2}$ shielded GTA welding, Materials Science and Engineering, A 380: 290-297.

[9] Niu, H.J., Chang, I.T.H., 1999, Instability of scan tracks of selective laser sintering of high speed steel powder, Scripta Materialia, 41/11:1229-1234.

[10] Mills, K.C., Keene, B.J., Brooks, R.F., Shirali, A., 1998, Marangoni effects in welding, in Marangoni and interfacial phenomena in materials processing, IOM Communications, London.

[11] Massalski, T.B., 1990, Binary alloy phase diagrams, Metals Park Ohio, Amer. Society for Metals

[12] Tolochko, N.K., Laoui, T., Khlopkov, Y.V., Mozzharov, S.E., Titov, V., Ignatiev, M.B., 2000, Absorptance of powder materials suitable for laser sintering, Rapid Prototyping Journal, 6/3:155-160.

[13] 1998, ASM Handbook, Volume 15: Casting.

[14] Rombouts, M., Froyen, L., Bourell, D., Kruth, J.P., 2005, Surface roughness after laser melting of iron based powders, Proc. $2^{\text {nd }}$ Int. Conf. on Adv. Res. in Virtual and Rapid Prototyping VRAP2005, 329-335.

[15] Delange, D.F., Postma, S., Meijer, J., 2003, Modelling and observation of laser welding: The effect of latent heat, Proc. of ICALEO 2003, Section C:154-162. 